\section{Nilómetro de Roda}

Mauricio Baros Profesor, Pontificia Universidad Católica de Chile y Universidad de Chile FOTOGRAFİAs Mauricio Baros

Las obras de infraestructura pueden ser muy diversas, sobre todo aquellas que buscan controlar fenómenos de la naturaleza. En este caso se habla del nilómetro de la isla de Roda, antigua construcción que permitió medir el nivel de las crecidas del río Nilo y así determinar el pago de impuestos de las cosechas que se obtendrían.

Siendo Egipto un país cuyo territorio es en un 96\% desierto y donde sólo un $4 \%$ corresponde a tierra cultivable y habitable, se entiende entonces por qué el manejo de los recursos hídricos fue una preocupación muy temprana desde los comienzos de su civilización. Ya en tiempos del antiguo Egipto se desarrollaron obras de infraestructura de riego y comunicaciones a gran escala, como lo fue el canal que unió al río Nilo con el Mar Rojo, construido por los faraones hacia el 1500 a.C. aproximadamente. ${ }^{1}$

Muchas de estas obras fueron de tal magnitud y calidad, que se siguieron utilizando incluso hasta la época islámica; constituyeron una verdadera estructura ósea sobre la pequeña franja verde de Egipto, sirvieron para regular las labores agrícolas y fueron determinantes en el trazado urbano de las ciudades.

Dentro de las innumerables obras realizadas con estos fines, quizás entre las más conspicuas estén los nilómetros.

Los nilómetros, como su nombre lo dice, fueron construcciones que permitían medir el caudal del Nilo en el punto del mayor nivel de su inundación, la cual ocurría entre los meses de agosto y septiembre. Según el volumen de este cauda se hacía un estimativo de la superficie de tierra que el río inundaría, la que luego de la retirada de las aguas se convertía en terreno cultivable. De acuerdo a esto se estimaba la producción agrícola y se cobraban los impuestos anuales sobre la misma; en el Egipto antiguo ellos solían ser muy altos, llegando casi a un 50\% de la producción. Por estos motivos los nilómetros eran construcciones importantísimas: cada nomo o provincia tenía uno, localizado dentro del templo, pues el templo era el centro no sólo religioso sino además económico y administrativo de cada provincia. El más conocido en la Antigüiedad era el de la isla Elefantina en el Nilo Alto, donde comenzaban las mediciones; en el período antiguo habrían existido aproximadamente 15 nilómetros entre la isla Elefantina y el delta del Nilo. Si bien existieron desde el Antiguo Egipto, si se habla de la época islámica en adelante el nilómetro por excelencia era el de la isla de Rawda o Roda en el área de El Cairo, dada la importancia política que llegó a tener. Llamado Mikyas Al-Nil (medidor del Nilo), se utilizó hasta el s. xIX.

Construido después de la conquista árabe, el nilómetro Mikyas al-Nil en Roda es la estructura más antigua de este período que sobrevive en su forma original en Egipto. Su función era medir la inundación anual del Nilo, para regular el nivel de aguas y establecer la tasa de impuesto que se pagaba al califato. La isla de Roda, opuesta a El Cairo viejo, puede ser considerada como el ápice del delta; es el último punto en donde el Nilo pasa con su caudal completo antes de disminuir su volumen en canales distributarios y, por lo tanto, se presenta como el punto más favorable para hacer las mediciones.

Los Omeyas ${ }^{2}$ habían construido anteriormente un nilómetro más simple; un muro graduado en una de las paredes del Nilo. El nilómetro actual fue construido en el año 861 por orden del califa Abbasí al-Mutawakkil (847-861) y diseñado por Kathir al-Farqhani, nativo de Farghona (hoy Uzbekistán Oriental), quien fue conocido en occidente como el astrónomo Alfraganus. La necesidad de contar con un profesional para su construcción se debe a que el nilómetro es un sofisticado instrumento basado en el principio de los vasos comunicantes.

El nilómetro de Roda consiste en un pozo de aproximadamente 9,5 m de profundidad, que se comunica con el Nilo a través de túneles excavados en tres niveles sobre su lado oriente. En el centro de este pozo existe una columna de $8,646 \mathrm{~m}$ de altura, de mármol graduada y dividida en 19 cúbitos $^{3}$. La base de este pozo es circular para permitir el fácil flujo de las corrientes que lo atraviesan, pero su parte central en cambio es cuadrada para aquietar las aguas, ya que es en este nivel donde se realizan las mediciones. Para ello existe una escalera que desciende por las paredes del pozo; los muros están ornamentados con inscrip ciones epigráficas de textos coránicos refiriéndose al agua, la vegetación y la prosperidad, mostrando con ello la importancia que se le asignaba a la estructura.
Infrastructure works can be very diverse, especially those that aim to control natural phenomena. This case discusses the nilometer of Rhodes Island, an ancient construction that measured the flood levels of the River Nile, helping to determine the taxing of crops that would be obtained.

Lo que el nilómetro anunciaba era vital para los gobernantes y para toda la población. Una subida ideal del río alcanzaba los 16 cúbitos, mientras que 19 cúbitos implicaban una inundación catastrófica. Menos de 16 traían sequía y hambre. Plinio decía que: "Cuando el agua se alza hasta solamente doce cúbitos, experimenta los horrores del hambre; cuando logra trece, el hambre sigue acechando; una subida de catorce cúbitos sólo provoca tristeza; una subida de quince cubitos permite alivianar los temores; mientras que un aumento de dieciséis trae como resultado felicidad sin límites" (Bostock y Riley, 1893).

Desde el período medieval y hasta el s. XIX, el nilómetro de Roda fue el punto de partida de una de las celebraciones más importantes de El Cairo: Fath al-Khalij, el festival de apertura del canal. El Khalij, que comenzaba en el punto opuesto de la isla de Roda, era un canal que bordeaba la ciudad medieval por el poniente e irrigaba sus jardines y campos. La inundación veraniega del Nilo llenaba el Khalij y sus estanques. Durante esta época la gente lo ocupaba para navegar por diversión y se recreaba en sus orillas. En la época previa a la inundación el Khalij era bloqueado con un dique de tierra y era abierto sólo cuando el Nilo alcanzaba los 16 cúbitos. La ceremonia de apertura era voceada por toda la ciudad y se realizaba acompañada de un verdadero desfile cívico y militar. En ese momento el gobernante lanzaba su espada sobre el dique y proclamaba la Wafa Allah-"Dios ha cumplido su promesa"-y los asistentes se abalanzaban sobre el dique con sus manos o lo que tuvieran para permitir que la aguas fluyeran en los canales subsidiarios. El califa, los sultanes y pashas asistían a esta celebración que duraba varios días, en las que circulaban embarcaciones muy decoradas, sobresaliendo entre ellas el bote del califa. Este festival duró hasta 1899, cuando el Khalij fue rellenado.

El boato e importancia alcanzados por esta ceremonia estriba que de ella dependía tanto la estabilidad política como la económica del califato, pues un año de sequía significaba hambrunas e inestabilidad política: de hecho varios importantes cambios políticos se produjeron luego de prolongadas sequías ${ }^{4}$. Tras el acto simbólico del festejo porque las aguas alcanzaban el nivel deseado, se escondía un motivo de orden económico: mientras más temprano ocurriera este hecho, más temprano comenzaba el cobro de impuestos respectivo. Esto motivó a que incluso algunos gobernantes adulteraran el sistema de medición para así proclamar la Wafa más tempranamente. ${ }^{5}$

Todo este ceremonial hizo que junto al nilómetro aparecieran otros edificios, como una mezquita para realizar las oraciones que acompañaban las celebraciones por la inundación y un palacio de banquetes para los gobernantes.

En los días previos, a la espera de la subida de las aguas, la columna del nilómetro era untada con azafrán y almizcle, para inducir a un buen nivel de aguas. Si las aguas no alcanzaban el nivel de los 16 cúbitos, las celebraciones eran canceladas y en su reemplazo se realizaban oraciones y ayunos para evitar la aparición de la sequía y el hambre. En una ocasión, después de un retraso de una inundación anual, el sultán Muayyad bebió agua del nilómetro en gesto de gratitud por haber alcanzado las aguas el nivel esperado.

El edificio actual ha sido varias veces restaurado. Su estructura es casi en su totalidad original a excepción de la cúpula cónica que fue reconstruida luego de una explosión durante la ocupación francesa de 1825 . No permanece en funciones, manteniéndose principalmente como monumento; ha sido reemplazado por un nilómetro dispuesto como un muro graduado sobre los bordes del río. Las represas construidas posteriormente, como la de Aswan, han permitido regular artificialmente el caudal del río. ARQ

\section{Bibliografía}

AA., W. Description de L'Egypte, Book 7, Etat Moderne. Gobierno de Francia, París, 1809-1822. | Ardagh, John. Nilometers. Royal Geographical Society, Monthly Record of Geography, Londres, 1889./ Bostock, John y Henry Riley. The natural history of Pliny. H. G. Bohn, Londres, 1893. 
1 Este canal fue posteriormente reparado por griegos y romanos $y$ se mantuvo en uso hasta la época

de la conquista islámica. Napoleón registró parte de lo que aún permanecía del canal, que habría sido cerrado definitivamente en 1811 .

Su existencia sería un antecedente para la construcción del canal

de Suez
${ }^{2}$ Los Omeyas fueron una dinastía $\begin{array}{ll}\text { arrabe que ejerció poder califal en } & \text { desastrosas condiciones produc } \\ \text { oriente -cuya capital era Damasco-y } & \text { por la sequía del año } 967 .\end{array}$

en Al-Ándalus -con capital en Córdoba- entre los s. vil y xı aproximadamente. (N. del Ed.)

${ }^{3}$ Un cúbito equivale a 0,524 m.

${ }^{4}$ Los fatimies conquistaron Egipto
(969) apoyados en los desórdenes y

5 "The real origin of the Sheikh's inaccuracy is probably to be found in the exigencies of Egyptian rulers in regard to levying the land-tax, which inmemorially was considered to become due when the Nile reached the 16th cubit." El real origen de

la inexactitud del Sheikh puede

encontrarse en las exigencias del

reglamento egipcio acerca de la re-

caudación de impuestos, que desd

tiempos inmemoriales debían ser

pagados cuando el Nilo alcanzaba

los 16 cúbitos (Ardagh, 1889).

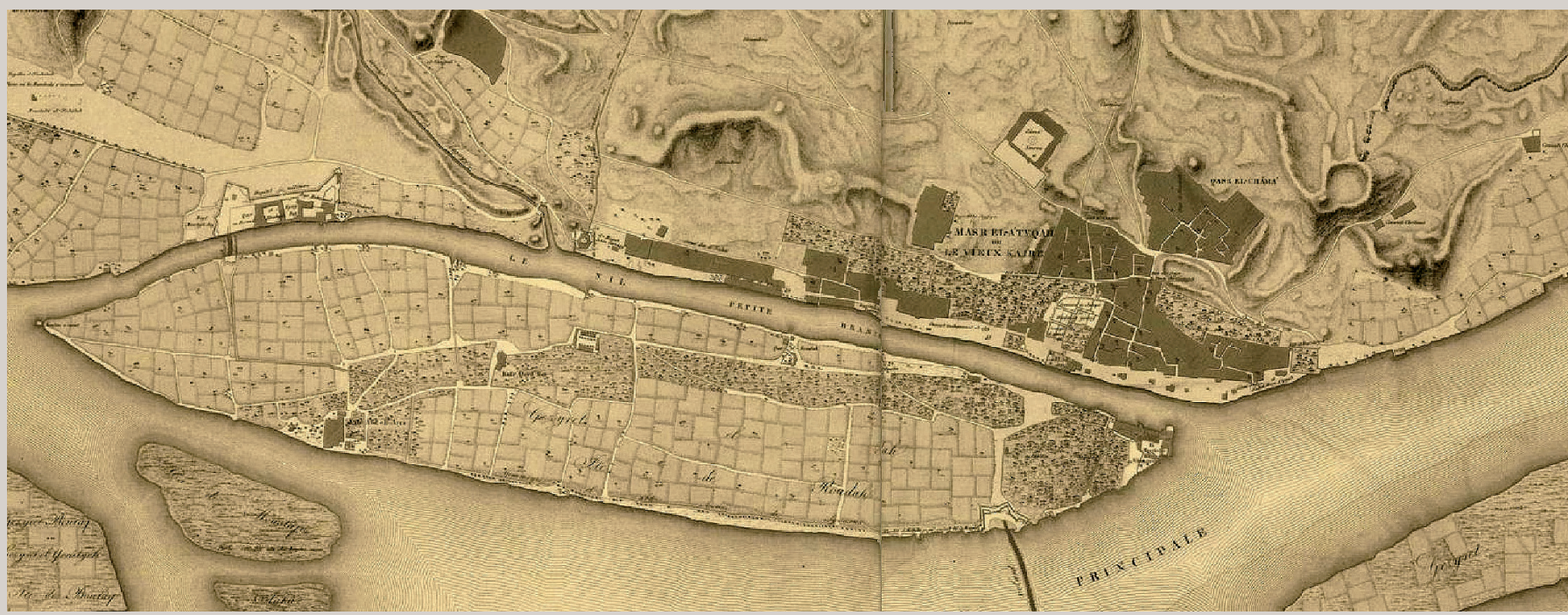

01 Plano de la isla de Roda. Fuente: Description de L'Egypte, Book 7, Etat Moderne, 1809-1822

\section{ILE DE ROUDAII .}

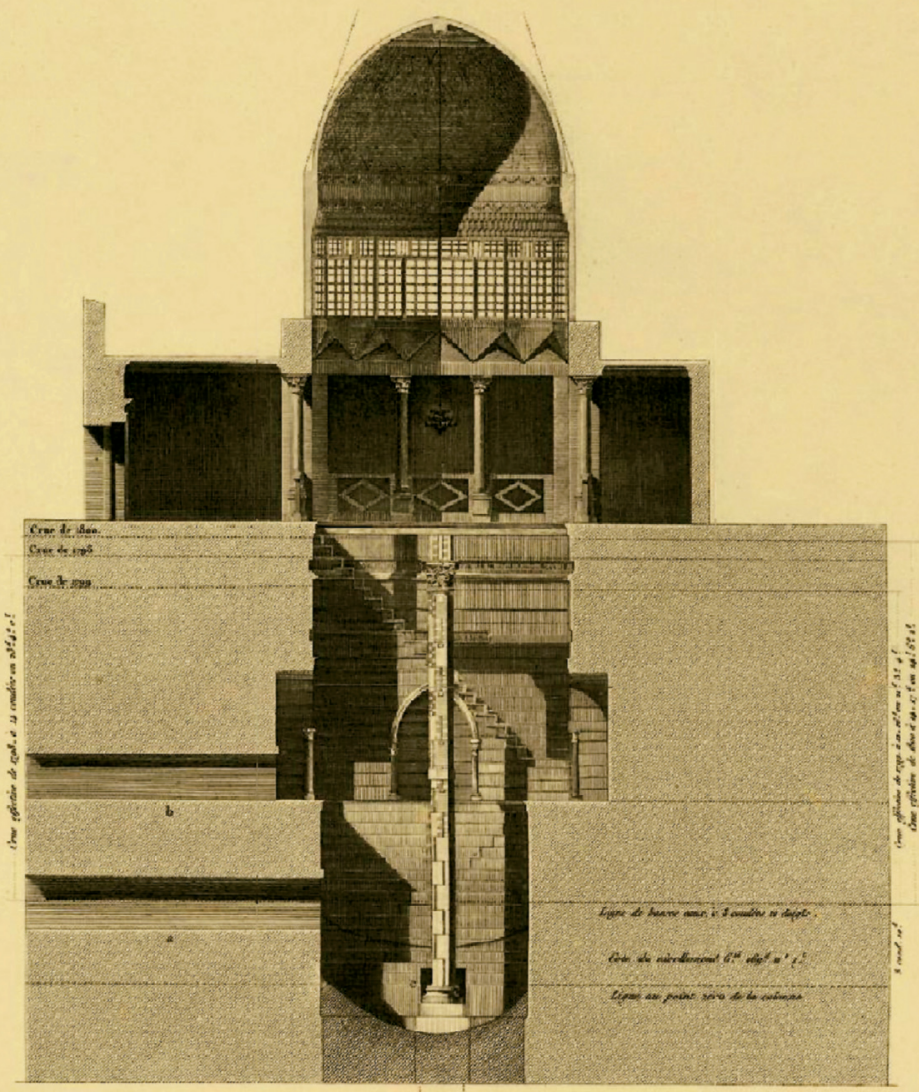

02 Corte nilómetro Mikyas Al-Nil. Fuente: Description de L'Egypte, Book 7, Etat Moderne, 1809-1822

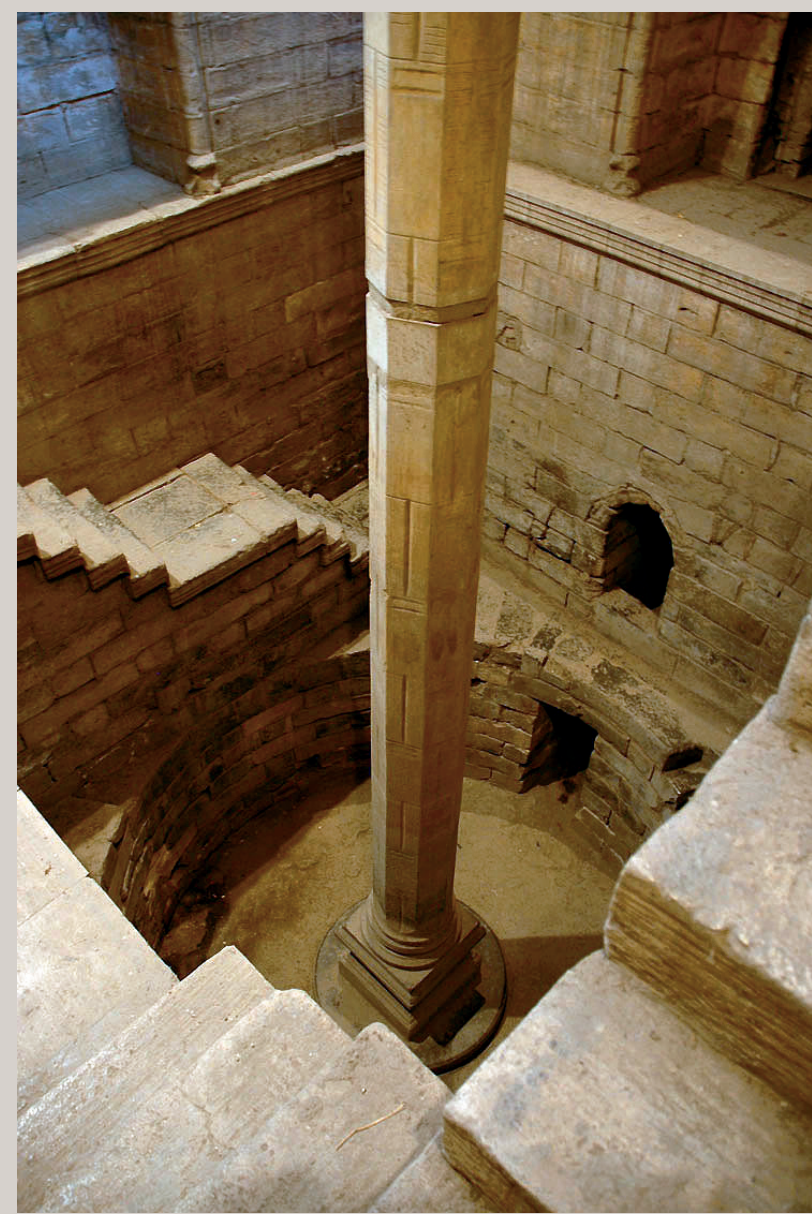

03 Nilómetro Mikyas Al-Nil 